\title{
Lixiviação de Sulfentrazone e Amicarbazone em Colunas de SOlo COM AdiçÃo de Óleo MINeral ${ }^{1}$
}

\author{
Leaching of Sulfentrazone and Amicarbazon in Soil Columns with Mineral Oil
}

\begin{abstract}
BACHEGA, T.F. ${ }^{2}$, PAVANI, M.CM.D. ${ }^{3}$, ALVES, P.L.C.A. ${ }^{3}$, SAES, L.P. ${ }^{4}$ e BOSCHIERO, M. ${ }^{5}$
RESUMO - O presente trabalho teve por objetivo avaliar a lixiviação dos herbicidas sulfentrazone e amicarbazone, com e sem óleo mineral, em área de plantio de cana-deaçúcar sobre um Latossolo Vermelho-Escuro, por meio de colunas de solo. Para avaliação da lixiviação, após acumuladas as precipitações de 35, 67 e $106 \mathrm{~mm}$, tubos de PVC de $10 \mathrm{~cm}$ de diâmetro, seccionados longitudinalmente, foram enterrados até a profundidade de $35 \mathrm{~cm}$, procurando-se manter a estrutura original do solo. Os tubos foram retirados, separados em suas metades e acondicionados em casa de vegetação, onde se semearam as plantas-teste sorgo (Sorghum bicolor) e corda-de-viola (Ipomoea nil) longitudinalmente ao longo do perfil de cada metade dos tubos. O delineamento experimental utilizado foi o de blocos ao acaso em esquema de parcelas subdivididas, com quatro repetições. As parcelas consistiram da aplicação dos dois herbicidas, adicionados ou não de adjuvante, e uma testemunha sem herbicida. Nas subparcelas estudaram-se as profundidades de percolação $(0,0-2,5 ; 2,5-5,0 ; 5,0-10 ; 10-15$; 15-20; 20-25; 25-30; e 30-35 cm). Aos 20 dias após a semeadura, determinou-se a matéria seca das plântulas. Observou-se que o sulfentrazone lixiviou até $10 \mathrm{~cm}$ de profundidade, mesmo com $106 \mathrm{~mm}$ de precipitação, sem efeito diferenciado do óleo. Os efeitos foram mais pronunciados para o sorgo. O amicarbazone não interferiu na matéria seca das plântulas de sorgo. Quanto à corda-de-viola, o herbicida sob precipitação de $35 \mathrm{~mm}$ reduziu o desenvolvimento das plântulas, independentemente da profundidade e sem efeito diferenciado do óleo; com $67 \mathrm{~mm}$ de precipitação, o herbicida lixiviou pelo solo, e o óleo mineral o manteve na camada mais superficial. Com $106 \mathrm{~mm}$, o herbicida foi totalmente lixiviado e não se constatou efeito do óleo.
\end{abstract}

Palavras-chave: percolação, herbicidas, sorção, profundidades.

\begin{abstract}
This study aimed to evaluate leaching of the herbicides sulfentrazone and amicarbazone, with and without mineral oil in a sugar cane plantation area on a Red Latosol, using soil columns. For leaching assessment, afterthe accumulated rainfall of 35, 67 and $106 \mathrm{~mm}, P V C$ tubes of $10 \mathrm{~cm}$ in diameter, sliced lengthwise, were buried at the depth of $35 \mathrm{~cm}$, managing to maintain the original structure of the soil. The tubes were removed, split into halves and placed in a greenhouse, where seeds of the test plant sorghum (Sorghum bicolor) and morning-glory (Ipomoea nil) were sown along the profile of each half of the tubes. The experimental design was randomized blocks with the treatments in split-plots with four replications. The plots consisted of two herbicides, with or without adjuvant, and a control without herbicide. The subplots were the depths (0.0-2.5; 2.5-5.0; 5.0-10, 10-15, 15-20, 20-25; 25-30; 30-35 cm). At 20 days after sowing, dry weight of the seedlings was determined. Sulfentrazone leached up to $10 \mathrm{~cm}$ deep, even with $106 \mathrm{~mm}$ of rainfall, without any differential effect of the oil. The effects were more pronounced for sorghum. Amicarbazone did not interfere in the dry weight of sorghum. For morning-glory, under a rainfall of $35 \mathrm{~mm}$, the herbicide reduced seedling development, regardless of depth and without any oil effect; with $67 \mathrm{~mm}$ of rainfall, the herbicide leached through soil with the mineral oil, maintaining it in the most superficial layer. With $106 \mathrm{~mm}$, the herbicide was totally leached and no oil effect was confirmed.
\end{abstract}

Keywords: percolation, herbicides, sorption, depths.

Recebido para publicação em 23.5.2008 e na forma revisada em 5.6.2008

2 Engo-Agro ${ }^{-}$, M.Sc., Ourofino Agronegócios, <t_bachega@yahoo.com.br>; ${ }^{3}$ Prof., Assistente, Dr., do Dep. de Biologia Aplicada à Agropecuária -FCAV/UNESP, Via de Acesso Prof. Paulo Donato Castellane, s/n, 14884-900 Jaboticabal-SP, <mcarmo@fcav.unesp.br> e <plalves@fcav.unesp.br>; ${ }^{4}$ Eng $\mathrm{a}-A g r{ }^{\mathrm{a}},{ }^{5}$ Engo - Agr ${ }^{\mathrm{o}}$, Unionagro.

Planta Daninha, Viçosa-MG, v. 27, n. 2, p. 363-370, 2009 


\section{INTRODUÇÃO}

A persistência de um produto fitossanitário no solo depende dos processos de dissipação, ou seja, dos processos de transferência, como evaporação, lixiviação, escoamento superficial e absorção por plantas, e também da taxa de degradação do produto (Graham-Bryce, 1981). Os processos de degradação podem ser químicos, físicos ou biológicos e podem resultar na mineralização total do produto ou na sua conversão em metabólitos. Entre esses processos, maior importância tem sido atribuída à degradação biológica, que está principalmente relacionada com a comunidade microbiana do solo (Graham-Bryce, 1981).

Os herbicidas sulfentrazone (2',4'-dichloro5-(4-difluoromethyl-4,5-dihydro-3 -methyl-5-oxo1H-1,2,4-triazol-1-yl)methanesulfonanilide) e amicarbazone $(1 \mathrm{H}-1,2,4$-triazole-1-carboxamide, 4-amino-N-(1,1-dimethyl-ethyl)-4,5-dihydro-3(1-methylethyl)-5-oxo) são utilizados em préemergência na cultura de cana-de-açúcar, para controle de plantas daninhas dicotiledôneas e monocotiledôneas. De acordo com Rodrigues e Almeida (2005), o mecanismo de ação principal do amicarbazone é a inibição da fotossíntese das plantas daninhas, atuando na reação de Hill (fotossistema II), inibindo o transporte de elétrons e paralisando a fixação de $\mathrm{CO}_{2}$ e a produção de ATPe NADPH, os quais são elementos essenciais ao crescimento das plantas. A morte das plantas, entretanto, pode ocorrer devido a outros processos, como a peroxidação de lipídeos e proteínas, promovendo a destruição das membranas e perda de clorofila.

O sulfentrazone, do grupo químico das triazolinonas, é um herbicida para aplicação preferencialmente em pré-emergência, que controla várias espécies de plantas daninhas, monocotiledôneas e dicotiledôneas, das culturas de cana-de-açúcar, soja, café e eucalipto, além do seu uso em pátios industriais. Ele apresenta solubilidade em água de $490 \mathrm{mg} \mathrm{L}^{-1}$ e pressão de vapor de $1 \times 10^{-9} \mathrm{~mm} \mathrm{Hg}$ a $25^{\circ} \mathrm{C}$. No solo, a mobilidade é moderada, de baixa adsorção, com $\mathrm{K}_{\mathrm{oc}}$ a 43, pK $\mathrm{a}$ a 6,56 e $\mathrm{K}_{\mathrm{ow}}$ a 1,48, sendo a decomposição microbiana a via mais importante de degradação do produto no solo; sua meia-vida em solos brasileiros é, em média, de 180 dias (Rodrigues \& Almeida, 2005).
O amicarbazone é um herbicida sistêmico pertencente ao grupo químico das triazolinonas e, segundo seu fabricante, possui enorme resistência à seca e longo período residual. Sua solubilidade é alta, da ordem de 4.600 ppm, considerado não volátil, pois sua pressão de vapor é de $0,975 \times 10^{-8} \mathrm{~mm} \mathrm{Hg}$ a $20^{\circ} \mathrm{C}$ e sua capacidade de adsorção varia entre 32,4 e 42,6 $\mathrm{mg} \mathrm{g}^{-1}$ de solo (Gimenes, 2004).

A tecnologia de aplicação é um fator importante para se obter um efetivo controle de plantas daninhas. Pulverizadores corretamente calibrados, pontas de pulverização sem defeito, temperatura do ar, umidade relativa do ar, velocidade dos ventos, presença de orvalho, entre outros fatores, somam para que a possibilidade de interferência das plantas daninhas seja diminuída pelo uso de herbicidas. Uma forma de otimizar a aplicação dos herbicidas é o uso de adjuvantes, como surfatantes e óleos minerais e vegetais. Contudo, em aplicações de pré-emergência, o uso de adjuvantes é mínimo. Quando em aplicações em pré-emergência, tem como característica diminuir a emissão de gotas-satélites, melhorando a distribuição da calda nas pontas de pulverização e, consequentemente, a deposição do herbicida no alvo.

O objetivo do presente trabalho foi estimar a lixiviação dos herbicidas sulfentrazone e amicarbazone em condição de campo, aplicados sobre solo cultivado com cana-de-açúcar, com e sem adição de óleo mineral.

\section{MATERIAL E MÉTODOS}

O experimento foi conduzido em área comercial de plantio de cana-de-açúcar pertencente à Usina Bonfim, no município de Santa Ernestina-SP, onde o solo foi classificado como Latossolo Vermelho-Amarelo, cujo histórico de aplicação de herbicidas indica que os últimos produtos aplicados na área foram ametrina e diuron, 17 meses antes da aplicação. As análises química e granulométrica do solo foram determinadas em amostras deformadas, nas camadas de 0-10, 10-20, 20-30 e 30-40 cm.

Os tratamentos constaram da aplicação de uma dose dos herbicidas sulfentrazone (600 g i.a. ha ${ }^{-1}$ ) e amicarbazone (1.050 g i.a. ha-1), com ou sem adição do óleo mineral a $0,5 \%$ (v/v), e uma testemunha sem herbicida. As 
parcelas apresentaram $5 \mathrm{~m}$ de comprimento por 5,6 m de largura e foram dispostas em blocos casualizados em quatro repetições.

A aplicação foi realizada após o plantio da cultura, com pulverizador costal de precisão à pressão constante (25 $\left.\mathrm{Lb} \mathrm{pol}^{-2}\right)$ mantida por $\mathrm{CO}_{2}$, munido de barra com quatro bicos tipo leque XR 11002, espaçados de $50 \mathrm{~cm}$, e regulado para um gasto de volume de calda de $200 \mathrm{~L} \mathrm{ha}^{-1}$. No momento da aplicação, iniciada às $10 \mathrm{~h}$ e finalizada as $11 \mathrm{~h}$, a temperatura do ar era de $29,3^{\circ} \mathrm{C}$; a umidade relativa do ar, de $39 \%$; a velocidade do vento, de $3 \mathrm{~km} \mathrm{~h}^{-1}$; e não havia nebulosidade.

Após a aplicação, foram realizadas amostragens do solo quando as precipitações naturais acumuladas atingiram os valores próximos de 35, 67 e $106 \mathrm{~mm}$. O acúmulo de chuva foi medido em uma estação agrometeorológica, a $1,5 \mathrm{~km}$ da área de aplicação. Nessas amostragens foram utilizados tubos de PVC de $10 \mathrm{~cm}$ de diâmetro, seccionados longitudinalmente, que foram enterrados no solo, na parte central da parcela, até a profundidade de $35 \mathrm{~cm}$. Após o enterrio, o tubo foi retirado com auxílio de cavadeira, procurando-se manter a integridade da estrutura original do solo. Os tubos contendo o solo foram acondicionados sobre as bancadas da casa de vegetação, para realização do bioensaio.

Para avaliação da profundidade de lixiviação dos herbicidas no perfil do solo, semearamse as plantas-teste sorgo (Sorghum bicolor) e corda-de-viola (Ipomoea nil), longitudinalmente ao longo do perfil de cada metade dos tubos, desde a sua superfície até $35 \mathrm{~cm}$, em intervalos aproximados de $1,0 \mathrm{~cm}$. Após 20 dias, fez-se a contagem do número de plantas emergidas, cortando-as na superfície, para determinação da matéria seca após secagem em estufa a $70{ }^{\circ} \mathrm{C}$ por 96 horas, obtendo-se a matéria seca por plântula.

Para o bioensaio, para cada precipitação e planta-teste, o delineamento experimental utilizado foi o de blocos ao acaso, em esquema de parcelas subdivididas com quatro repetições. As parcelas consistiram da aplicação de dois herbicidas (sulfentrazone e amicarbazone), com e sem adição de óleo mineral, e uma testemunha sem herbicida; nas subparcelas, estudaram-se as profundidades da lixiviação estratificada em faixas de $0-2,5 ; 2,5-5,0 ; 5,0-10$; 10-15; 15-20; 20-25; 25-30; e 30-35 cm.

Os dados obtidos foram transformados em arc sen $\sqrt{ }(x+0,30)$ e submetidos à análise de variância pelo teste $\mathrm{F}$. Quando significativas ( $p<0,01$ ou $p<0,05$ ), as médias foram comparadas pelo teste de Tukey a $5 \%$ de probabilidade.

\section{RESULTADOS E DISCUSSÃO}

Até os $30 \mathrm{~cm}$ de profundidade, o solo da área experimental sempre manteve praticamente os mesmos valores de $\mathrm{pH}$, matéria orgânica e cálcio; quanto às demais características, os valores diminuíram com a profundidade de amostragem do solo, sendo esse efeito mais acentuado para todas as características na camada de $30-40 \mathrm{~cm}$ (Tabela 1). A granulometria do solo não se alterou com a profundidade (Tabela 2).

Analisando a matéria seca das plântulas desenvolvidas no perfil do solo, não houve interação entre profundidade e herbicidas na precipitação de $67 \mathrm{~mm}$ para Sorghum bicolor e de $35 \mathrm{~mm}$ para Ipomoea nil (Tabela 3); nas demais precipitações, a interação foi significativa para as espécies, ou seja, 35 e $106 \mathrm{~mm}$ para S. bicolor e 67 e $106 \mathrm{~mm}$ para I. nil (Tabelas 4, 5 e 6).

Tabela 1 - Resultados da análise química de amostras coletadas nas diferentes profundidades do solo que recebeu aplicação dos herbicidas

\begin{tabular}{|c|c|c|c|c|c|c|c|c|c|c|}
\hline \multirow{2}{*}{ Camada } & $\mathrm{pH}$ & M.O. & Pres. & $\mathrm{K}$ & $\mathrm{Ca}$ & $\mathrm{Mg}$ & $\mathrm{H}+\mathrm{AL}$ & SB & $\mathrm{T}$ & \multirow{2}{*}{$\begin{array}{c}\mathrm{V} \\
(\%)\end{array}$} \\
\hline & $\left(\mathrm{CaCl}_{2}\right)$ & $\left(\mathrm{g} \mathrm{dm}^{3}\right)$ & $\left(\mathrm{mg} \mathrm{dm}^{3}\right)$ & \multicolumn{6}{|c|}{$\left(\mathrm{mmolc} \mathrm{dm}^{3}\right)$} & \\
\hline $0-10$ & 4,9 & 13 & 18 & 1,5 & 14 & 7 & 22 & 22,5 & 44,5 & 51 \\
\hline $10-20$ & 4,8 & 13 & 15 & 1,0 & 13 & 6 & 25 & 20,0 & 45,0 & 44 \\
\hline $20-30$ & 4,8 & 12 & 10 & 1,0 & 12 & 5 & 25 & 18,0 & 43,0 & 42 \\
\hline $30-40$ & 4,4 & 10 & 8 & 0,9 & 8 & 5 & 31 & 13,9 & 44,9 & 31 \\
\hline
\end{tabular}


Tabela 2 - Resultados da análise granulométrica de amostras coletadas nas diferentes profundidades do solo que recebeu aplicação dos herbicidas

\begin{tabular}{|l|c|c|c|c|}
\hline \multirow{2}{*}{$\begin{array}{c}\text { Granulometria } \\
\left(\mathrm{g} \mathrm{kg}^{-1}\right)\end{array}$} & \multicolumn{4}{|c|}{ Profundidade $(\mathrm{cm})$} \\
\cline { 2 - 5 } & $0-10$ & $10-20$ & $20-30$ & $30-40$ \\
\hline Argila & 270 & 270 & 280 & 290 \\
\hline Limo & 50 & 40 & 50 & 50 \\
\hline Areia fina & 290 & 280 & 270 & 270 \\
\hline Areia grossa & 390 & 410 & 400 & 390 \\
\hline Classe Textural & Média & Média & Média & Média \\
\hline
\end{tabular}

Tabela 3 - Matéria seca (g por planta) da parte aérea de plântulas de corda-de-viola e de sorgo em resposta à precipitação, avaliada aos 20 dias após a semeadura, em relação a herbicidas e profundidades, Jaboticabal, 2007

\begin{tabular}{|l|c|c|}
\hline \multirow{2}{*}{ Tratamento } & \multicolumn{2}{|c|}{ Espécie/precipitação } \\
\cline { 2 - 3 } & $\begin{array}{c}\text { Corda-de- } \\
\text { viola/35 mm }\end{array}$ & Sorgo/67 mm \\
\hline Herbicidas & Matéria Seca $(\mathrm{g}$ por planta) \\
\hline Sulfentrazone & $1,35 \mathrm{AB}{ }^{1}$ - & $1,26 \mathrm{C}$ \\
\hline Sulfentrazone + Adj & $1,31 \mathrm{AB}$ & $1,28 \mathrm{BC}$ \\
\hline Amicarbazone & $1,17 \mathrm{~B}$ & $1,33 \mathrm{ABC}$ \\
\hline Amicarbazone + Adj & $1,19 \mathrm{~B}$ & $1,35 \mathrm{AB}$ \\
\hline Testemunha & $1,39 \mathrm{~A}$ & $1,38 \mathrm{~A}$ \\
\hline CV (\%) & 17,36 & 7,02 \\
\hline DMS(herb) & 0,18 & 0,07 \\
\hline F (herb) & $6,00^{* *}$ & $8,85^{* *}$ \\
\hline Profundidades (cm) & & \\
\hline $0-2,5$ & $1,11 \mathrm{D}$ & $1,26 \mathrm{C}$ \\
\hline $2,5-5,0$ & $1,11 \mathrm{D}$ & $1,27 \mathrm{BC}$ \\
\hline $5,0-10,0$ & $1,19 \mathrm{CD}$ & $1,34 \mathrm{~A}$ \\
\hline $10,0-15,0$ & $1,27 \mathrm{BC}$ & $1,32 \mathrm{ABC}$ \\
\hline $15,0-20,0$ & $1,40 \mathrm{AB}$ & $1,35 \mathrm{~A}$ \\
\hline $20,0-25,0$ & $1,38 \mathrm{AB}$ & $1,32 \mathrm{ABC}$ \\
\hline $25,0-30,0$ & $1,41 \mathrm{~A}$ & $1,35 \mathrm{~A}$ \\
\hline $30,0-35,0$ & $1,39 \mathrm{AB}$ & $1,32 \mathrm{ABC}$ \\
\hline CV (\%) & 10,36 & 5,69 \\
\hline F (prof) & $18,99^{* *} \cdots \cdots$ & $4,01^{* *}$ \\
\hline DMS (prof) & 0,13 & 0,07 \\
\hline F (interação) & $1,18^{\text {ns }}$ & $1,57^{\text {ns }}$ \\
\hline
\end{tabular}

1/ Médias seguidas por mesma letra na coluna não diferem entre si a $5 \%$ de probabilidade pelo teste de Tukey.

** significativo a $1 \%$ de probabilidade pelo teste de Tukey; e ${ }^{\text {ns }}$ não significativo a $5 \%$ de probabilidade pelo teste de Tukey

Na Tabela 3, verifica-se redução na matéria seca de $I$. nil com a aplicação de amicarbazone e precipitação acumulada de $35 \mathrm{~mm}$, sem haver efeito do adjuvante, enquanto o sulfentrazone não afetou essa característica. Quanto ao efeito da profundidade, verificou-se redução na matéria seca das plântulas até $10 \mathrm{~cm}$, que pode se estender até $15 \mathrm{~cm}$ quando comparada a $25,0-30,0 \mathrm{~cm}$. Na precipitação acumulada de $67 \mathrm{~mm}$, a matéria seca das plântulas de $S$. bicolor foi menor com a aplicação de sulfentrazone isolado ou com adjuvante, quando comparada à da testemunha, ao passo que o amicarbazone não afetou esta característica, independentemente da profundidade. Em relação ao fator profundidade, verificou-se menor matéria seca nas camadas de 0-2,5 e 2,5-5,0 cm, quando comparada à das camadas de 5-10, 15-20 e $25-30 \mathrm{~cm}$.

Na Tabela 4 são apresentados os resultados da interação na precipitação de $35 \mathrm{~mm}$ para S. bicolor. O sulfentrazone reduziu significativamente a matéria seca do $S$. bicolor até a profundidade de $10 \mathrm{~cm}$, mas com a adição do adjuvante esse efeito se limitou aos $5 \mathrm{~m}$ superficiais (Tabela 4). Vivian et al. (2006), estudando por meio de bioensaios amostras de um Argissolo Vermelho-Amarelo coletadas em campo após a aplicação de sulfentrazone, sem a manutenção da estrutura original do solo, verificaram redução bem evidente da matéria seca da parte aérea, da altura e dos indices de fitotoxicidade de 0 a $10 \mathrm{~cm}$ no perfil do solo coletado, confirmando, dessa forma, a capacidade dessortiva desse herbicida no solo. Rossi et al. (2005), avaliando a lixiviação de sulfentrazone em colunas de PVC em função de diferentes índices pluviométricos $(30,60$ e $90 \mathrm{~mm}$ ), sob condições de casa de vegetação, utilizando Latossolo Vermelho e Chernossolo, relataram que neste último houve uniformidade da distribuição do produto ao longo do tubo, proporcional à precipitação, e no Latossolo Vermelho o sulfentrazone foi pouco móvel, permanecendo na camada superficial, independentemente da precipitação.

Nessa mesma precipitação, o amicarbazone, aplicado isolado ou em mistura com óleo mineral, não causou redução da matéria seca de $S$. bicolor em nenhuma das profundidades avaliadas, indicando que esta poderia não ser uma planta-teste indicada para esse herbicida; uma outra possibilidade é que o produto lixiviou por todo o perfil do solo, devido à sua elevada solubilidade, e a concentração remanescente não causou intoxicação às plantas. Ao avaliar a eficiência agronômica do amicarbazone em diferentes posicionamentos em relação à camada de palha de cana-de-açúcar e seu comportamento sob efeito da chuva simulada antes ou após aplicação do herbicida, sobre diversas 
plantas daninhas, Negrisoli et al. (2007) mencionaram que a espécie $I$. grandifolia mostrouse mais sensivel ao amicarbazone, demonstrando elevada sensibilidade aos tratamentos com o herbicida. Para Brachiaria plantaginea e $B$. decumbens, as porcentagens de controle foram altas nos tratamentos em que o herbicida atingiu o solo, independentemente se aplicado diretamente sobre este ou lixiviado pela simulação de chuva após a aplicação do herbicida, porém o sorgo não foi afetado. Toledo et al. (2004) relataram que o amicarbazone é absorvido pelo sistema radicular e translocado via xilema; no entanto, quando aplicado em pós-emergência, prevalece a absorção foliar, sendo predominante a ação de contato.

Com 106 mm de precipitação acumulada na área, a avaliação de matéria seca das plantas de $S$. bicolor indicou que o herbicida sulfentrazone isolado novamente se manteve até a profundidade de $10 \mathrm{~cm}$, enquanto com o adjuvante esse efeito foi observado apenas até os $2,5 \mathrm{~cm}$ de profundidade, mas podendo se estender até $10 \mathrm{~cm}$, se comparado à testemunha (Tabela 5). Esses resultados contradizem

Tabela 4 - Desdobramento da interação entre herbicidas e profundidades para os valores de matéria seca da parte aérea de plântulas de sorgo e profundidade de lixiviação dos herbicidas, após $35 \mathrm{~mm}$ de precipitação. Jaboticabal, 2007

\begin{tabular}{|c|c|c|c|c|c|}
\hline \multirow{2}{*}{$\begin{array}{l}\text { Profundidade } \\
\quad(\mathrm{cm})\end{array}$} & \multicolumn{5}{|c|}{ Herbicida } \\
\hline & Sulfentrazone & Sulfentrazone + Adj & Amicarbazone & Amicarbazone + Adj & Testemunha \\
\hline $0,0-2,5$ & $1,17 \mathrm{C} \mathrm{b}^{\underline{1}}$ & $1,17 \mathrm{BC} \mathrm{b}$ & $1,29 \mathrm{~A} \mathrm{ab}$ & $1,26 \mathrm{~A}$ ab & $1,37 \mathrm{~A} \mathrm{a}$ \\
\hline $2,5-5,0$ & $1,14 \mathrm{C} \mathrm{c}$ & $1,16 \mathrm{C} \mathrm{bc}$ & $1,29 \mathrm{~A} a b c$ & $1,30 \mathrm{~A} \mathrm{ab}$ & $1,42 \mathrm{~A} \mathrm{a}$ \\
\hline $5,0-10,0$ & $1,18 \mathrm{C} \mathrm{b}$ & $1,24 \mathrm{ABC} b$ & $1,31 \mathrm{~A} \mathrm{ab}$ & $1,32 \mathrm{~A} \mathrm{ab}$ & $1,41 \mathrm{~A} \mathrm{a}$ \\
\hline $10,0-15,0$ & $1,30 \mathrm{~B} \mathrm{Ca}$ & $1,33 \mathrm{AB}$ a & $1,35 \mathrm{~A} \mathrm{a}$ & $1,37 \mathrm{~A} \mathrm{a}$ & $1,43 \mathrm{~A} \mathrm{a}$ \\
\hline $15,0-20,0$ & $1,43 \mathrm{~A} \mathrm{Ba}$ & $1,40 \mathrm{~A} \mathrm{a}$ & $1,34 \mathrm{~A} \mathrm{a}$ & $1,34 \mathrm{~A} \mathrm{a}$ & $1,39 \mathrm{~A} \mathrm{a}$ \\
\hline $20,0-25,0$ & $1,48 \mathrm{~A} \mathrm{a}$ & $1,37 \mathrm{~A} \mathrm{a}$ & $1,37 \mathrm{~A} \mathrm{a}$ & $1,37 \mathrm{~A} \mathrm{a}$ & $1,45 \mathrm{~A} \mathrm{a}$ \\
\hline $25,0-30,0$ & $1,42 \mathrm{AB}$ a & $1,38 \mathrm{~A} \mathrm{a}$ & $1,39 \mathrm{~A} \mathrm{a}$ & $1,38 \mathrm{~A} \mathrm{a}$ & $1,43 \mathrm{~A} \mathrm{a}$ \\
\hline $30,0-35,0$ & $1,40 \mathrm{AB}$ a & $1,33 \mathrm{AB}$ a & $1,39 \mathrm{~A} \mathrm{a}$ & $1,41 \mathrm{~A} \mathrm{a}$ & $1,43 \mathrm{~A} \mathrm{a}$ \\
\hline \multicolumn{2}{|c|}{$\mathrm{F}($ herb $)-8,58^{* *}$} & \multicolumn{2}{|c|}{$\mathrm{F}($ prof $)-14,20^{* *}$} & \multicolumn{2}{|c|}{$\mathrm{F}($ Interação $)-1,99 * *$} \\
\hline \multicolumn{2}{|c|}{$\mathrm{CV}(\%)$ herb $-6,55$} & \multicolumn{4}{|c|}{ CV $(\%)$ prof $-5,70$} \\
\hline \multicolumn{6}{|c|}{ DMS (prof) - 0,16} \\
\hline \multicolumn{6}{|c|}{ DMS (herb) $-0,15$} \\
\hline
\end{tabular}

1/ Médias seguidas de mesma letra não diferem significativamente entre si pelo teste de Tukey a 5\% de probabilidade. Letras maiúsculas, na coluna, comparam as diferentes profundidades. Letras minúsculas, na linha, comparam os tratamentos com aplicação dos herbicidas. ** significativo a $1 \%$ de probabilidade pelo teste de Tukey.

Tabela 5 - Desdobramento da interação entre herbicidas e profundidades para os valores de matéria seca da parte aérea de plântulas de sorgo e profundidade de lixiviação dos herbicidas, após $106 \mathrm{~mm}$ de precipitação. Jaboticabal, 2007

\begin{tabular}{|c|c|c|c|c|c|}
\hline \multirow{2}{*}{$\begin{array}{l}\text { Profundidade } \\
(\mathrm{cm})\end{array}$} & \multicolumn{5}{|c|}{ Herbicida } \\
\hline & Sulfentrazone & Sulfentrazone + Adj & Amicarbazone & Amicarbazone + Adj & Testemu nha \\
\hline $0,0-2,5$ & $1,15 \mathrm{C} \mathrm{d}^{\underline{1}}$ & $1,17 \mathrm{~B} \mathrm{~cd}$ & $1,61 \mathrm{~A} \mathrm{a}$ & $1,36 \mathrm{~A} \mathrm{bc}$ & $1,42 \mathrm{~A} \mathrm{ab}$ \\
\hline $2,5-5,0$ & $1,19 \mathrm{BC} \mathrm{c}$ & $1,20 \mathrm{AB} b c$ & $1,49 \mathrm{AB} a b$ & $1,39 \mathrm{~A} \mathrm{ab}$ & $1,33 \mathrm{~A} \mathrm{abc}$ \\
\hline $5,0-10,0$ & $1,21 \mathrm{BC} \mathrm{b}$ & $1,21 \mathrm{AB} \mathrm{b}$ & $1,38 \mathrm{~B} \mathrm{ab}$ & $1,35 \mathrm{~A}$ ab & $1,41 \mathrm{~A} \mathrm{a}$ \\
\hline $10,0-15,0$ & $1,36 \mathrm{AB}$ a & $1,35 \mathrm{AB}$ a & $1,39 \mathrm{~B} \mathrm{a}$ & $1,41 \mathrm{~A} \mathrm{a}$ & $1,35 \mathrm{~A} \mathrm{a}$ \\
\hline $15,0-20,0$ & $1,33 \mathrm{ABC}$ a & $1,35 \mathrm{AB}$ a & $1,47 \mathrm{~A} \mathrm{ba}$ & $1,39 \mathrm{~A} \mathrm{a}$ & $1,39 \mathrm{~A} \mathrm{a}$ \\
\hline $20,0-25,0$ & $1,34 \mathrm{AB}$ a & $1,37 \mathrm{~A} \mathrm{a}$ & $1,36 \mathrm{~B} \mathrm{a}$ & $1,43 \mathrm{~A} \mathrm{a}$ & $1,38 \mathrm{~A} \mathrm{a}$ \\
\hline $25,0-30,0$ & $1,32 \mathrm{ABC}$ a & $1,34 \mathrm{~A}$ ba & $1,39 \mathrm{~B} \mathrm{a}$ & $1,38 \mathrm{~A} \mathrm{a}$ & $1,41 \mathrm{~A} \mathrm{a}$ \\
\hline $30,0-35,0$ & $1,40 \mathrm{~A} \mathrm{a}$ & $1,30 \mathrm{~A} \mathrm{ba}$ & $1,38 \mathrm{~B} \mathrm{a}$ & $1,47 \mathrm{~A} \mathrm{a}$ & $1,41 \mathrm{~A} \mathrm{a}$ \\
\hline \multicolumn{2}{|c|}{$\mathrm{F}($ herb $)-5,94 * *$} & \multicolumn{2}{|c|}{$F($ prof $)-2,61^{*}$} & \multicolumn{2}{|c|}{$\mathrm{F}($ Interação $)-2,81^{* *}$} \\
\hline \multicolumn{2}{|c|}{ CV $(\%)$ herb $-11,52$} & \multicolumn{4}{|c|}{ CV $(\%)$ prof $-6,21$} \\
\hline \multicolumn{2}{|c|}{ DMS (prof) $-0,19$} & & & & \\
\hline
\end{tabular}

1/ Médias seguidas de mesma letra não diferem significativamente entre si pelo teste de Tukey a 5\% de probabilidade. Letras maiúsculas, na coluna, comparam as diferentes profundidades. Letras minúsculas, na linha, comparam os tratamentos com aplicação dos herbicidas. $* *, *$ significativo a $1 \%$ e $5 \%$ de probabilidade pelo teste de Tukey, respectivamente. 
Tabela 6 - Desdobramento da interação entre herbicidas e profundidades para os valores de matéria seca da parte aérea de plântulas de corda-de-viola ( $($. nil) e profundidade de lixiviação dos herbicidas, após $67 \mathrm{~mm}$ de precipitação. Jaboticabal, 2007

\begin{tabular}{|c|c|c|c|c|c|}
\hline \multirow{2}{*}{$\begin{array}{l}\text { Profundidade } \\
\qquad(\mathrm{cm})\end{array}$} & \multicolumn{5}{|c|}{ Herbicida } \\
\hline & Sulfent razone & Sulfentrazone + Adj & Amicarbazone & Amicarbazone + Adj & Testemunha \\
\hline $0,0-2,5$ & $1,18 \mathrm{~A} \mathrm{bc}$ & $1,22 \mathrm{~A} \mathrm{bc}$ & $1,23 \mathrm{~A} \mathrm{ab}$ & $0,99 \mathrm{C} \mathrm{c}$ & $1,47 \mathrm{~A} \mathrm{a}$ \\
\hline $2,5-5,0$ & $1,21 \mathrm{~A} \mathrm{a}$ & $1,22 \mathrm{~A} \mathrm{a}$ & $1,15 \mathrm{~A} \mathrm{a}$ & $1,14 \mathrm{BC} \mathrm{a}$ & $1,36 \mathrm{~A} \mathrm{a}$ \\
\hline $5,0-10,0$ & $1,19 \mathrm{~A} \mathrm{a}$ & $1,29 \mathrm{~A} \mathrm{a}$ & $1,21 \mathrm{~A} \mathrm{a}$ & $1,17 \mathrm{ABC}$ a & $1,34 \mathrm{~A} \mathrm{a}$ \\
\hline $10,0-15,0$ & $1,28 \mathrm{~A} \mathrm{a}$ & $1,27 \mathrm{~A} \mathrm{a}$ & $1,27 \mathrm{~A} \mathrm{a}$ & $1,17 \mathrm{ABC}$ a & $1,34 \mathrm{~A} \mathrm{a}$ \\
\hline $15,0-20,0$ & $1,30 \mathrm{~A} \mathrm{a}$ & $1,28 \mathrm{~A} \mathrm{a}$ & $1,28 \mathrm{~A} \mathrm{a}$ & $1,30 \mathrm{AB}$ a & $1,33 \mathrm{~A} \mathrm{a}$ \\
\hline $20,0-25,0$ & $1,30 \mathrm{~A} \mathrm{a}$ & $1,37 \mathrm{~A} \mathrm{a}$ & $1,27 \mathrm{~A} \mathrm{a}$ & $1,35 \mathrm{AB}$ a & $1,43 \mathrm{~A} \mathrm{a}$ \\
\hline $25,0-30,0$ & $1,31 \mathrm{~A} \mathrm{a}$ & $1,36 \mathrm{~A} \mathrm{a}$ & $1,27 \mathrm{~A} \mathrm{a}$ & $1,40 \mathrm{~A} \mathrm{a}$ & $1,29 \mathrm{~A} \mathrm{a}$ \\
\hline $30,0-35,0$ & $1,29 \mathrm{~A} \mathrm{a}$ & $1,22 \mathrm{~A} \mathrm{a}$ & $1,23 \mathrm{~A} \mathrm{a}$ & $1,39 \mathrm{~A} \mathrm{a}$ & $1,40 \mathrm{~A} \mathrm{a}$ \\
\hline \multicolumn{2}{|c|}{$\mathrm{F}($ herb $)-2,84^{\mathrm{ns}}$} & \multicolumn{2}{|c|}{$\mathrm{F}$ (prof) $-3,84^{* *}$} & \multicolumn{2}{|c|}{$\mathrm{F}($ Interação $)-1,68^{*}$} \\
\hline \multicolumn{2}{|c|}{ CV $(\%)$ herb $-14,04$} & \multicolumn{4}{|c|}{ CV $(\%)$ prof $-8,72$} \\
\hline \multicolumn{6}{|c|}{ DMS (prof) $-0,24$} \\
\hline \multicolumn{6}{|c|}{ DMS (herb) $-0,24$} \\
\hline
\end{tabular}

${ }^{1 /}$ Médias seguidas de mesma letra não diferem significativamente entre si pelo teste de Tukey a $5 \%$ de probabilidade. Letras maiúsculas, na coluna, comparam as diferentes profundidades. Letras minúsculas, na linha, comparam os tratamentos com aplicação dos herbicidas. **, * significativo a $1 \%$ e $5 \%$ de probabilidade pelo teste de Tukey, respectivamente; ${ }^{\text {ns }}$ não significativo a $5 \%$ de probabilidade pelo teste de Tukey.

os obtidos por Rodrigues et al. (1999), que constataram que o sulfentrazone foi lixiviado para camadas de profundidade superior a $10 \mathrm{~cm}$ no perfil do solo, quando submetido à irrigação de $20 \mathrm{~mm}, 24$ horas após a sua pulverização. Rossi et al. (2003) avaliaram em colunas de PVC a mobilidade do sulfentrazone em condições laboratoriais e constataram pequena mobilidade do herbicida em Nitossolo Vermelho (até $7,5 \mathrm{~cm}$ ) e em Neossolo Quartzarênico (até 12,5 cm), mesmo quando submetido a $90 \mathrm{~mm}$ de precipitação pluvial. Esses autores observaram ainda que um dos fatores que influenciaram a ação do herbicida foi a saturação do solo, visto que, quanto maior foi o indice pluviométrico, maior foi a intensidade de injúria nas plantas; contudo, esse efeito não foi observado no presente trabalho. Alves et al. (1999) verificaram em LV que o sulfentrazone proporcionou excelente controle da tiririca, independentemente da umidade, enquanto em um NV o herbicida somente controlou a planta daninha quando a umidade do substrato era ou foi elevada para $90 \%(\mathrm{p} / \mathrm{p})$.

Aos $67 \mathrm{~mm}$ de precipitação (Tabela 6), observou-se que o sulfentrazone, com ou sem adjuvante, diminuiu a matéria seca das plântulas de $I$. nil na camada superficial (até $2,5 \mathrm{~cm})$. No entanto, essa diferença só foi significativa na profundidade de $0,0-2,5 \mathrm{~cm}$, independentemente da adição do adjuvante. Com base nos resultados da análise química do solo (Tabela 1), observaram-se baixos valores de $\mathrm{pH}(4,9)$ em todas as camadas. Esse resultado, aliado à baixa mobilidade do herbicida, corrobora as observações feitas por Alves et al. (2004), os quais mencionaram que a mobilidade e a capacidade de adsorção do sulfentrazone no solo ocorrem principalmente quando o $\mathrm{pH}$ deste for muito abaixo do pKa do herbicida, reduzindo sua eficiência em campo.

Os resultados para o herbicida amicarbazone na precipitação de $67 \mathrm{~mm}$ (Tabela 6) demonstraram que houve redução acentuada da matéria seca da corda-de-viola na profundidade de $0,0-2,5 \mathrm{~cm}$ quando foi adicionado adjuvante ao herbicida. O mesmo não ocorreu quando o herbicida foi aplicado sem óleo mineral. Dias et al. (2006), ao avaliarem a eficiência de amicarbazone simulando precipitação acumulada de três meses consecutivos, em aplicação pré-emergente com e sem adição do adjuvante aquil éster sobre I. grandifolia, Merremia cissoides, B. decumbens e Panicum maximum, concluíram que os períodos trimestrais que propiciaram as maiores condições de umidade afetaram negativamente o desempenho do amicarbazone. $\mathrm{O}$ adjuvante aquil éster beneficiou o desempenho do amicarbazone no controle de gramineas, principalmente nas 
Tabela 7 - Desdobramento da interação entre herbicidas e profundidades para os valores de matéria seca da parte aérea de plântulas de corda-de-viola (I. nil) e profundidade de lixiviação dos herbicidas, após 106 mm de precipitação. Jaboticabal, 2007

\begin{tabular}{|c|c|c|c|c|c|}
\hline \multirow{2}{*}{$\begin{array}{l}\text { Profundidade } \\
(\mathrm{cm})\end{array}$} & \multicolumn{5}{|c|}{ Herbicida } \\
\hline & Sulfentrazone & Sulfentrazone + Adj & Amicarbazone & Amicarbazone + Adj & Testemunha \\
\hline $0,0-2,5$ & $1,16 \mathrm{~B} \mathrm{c}$ & $1,25 \mathrm{~A} \mathrm{bc}$ & $1,33 \mathrm{~A} \mathrm{ab}$ & $1,34 \mathrm{AB}$ ab & $1,41 \mathrm{Aa}$ \\
\hline $2,5-5,0$ & $1,21 \mathrm{AB} \mathrm{b}$ & $1,25 \mathrm{~A} \mathrm{~b}$ & $1,26 \mathrm{~A} \mathrm{ab}$ & $1,33 \mathrm{AB}$ ab & $1,42 \mathrm{~A} \mathrm{a}$ \\
\hline $5,0-10,0$ & $1,22 \mathrm{AB}$ a & $1,26 \mathrm{~A} \mathrm{a}$ & $1,38 \mathrm{~A} \mathrm{a}$ & $1,32 \mathrm{~B} \mathrm{a}$ & $1,36 \mathrm{~A} \mathrm{a}$ \\
\hline $10,0-15,0$ & $1,30 \mathrm{AB}$ a & $1,34 \mathrm{~A} \mathrm{a}$ & $1,38 \mathrm{~A} \mathrm{a}$ & $1,38 \mathrm{AB}$ a & $1,39 \mathrm{~A} \mathrm{a}$ \\
\hline $15,0-20,0$ & $1,34 \mathrm{~A} \mathrm{a}$ & $1,38 \mathrm{~A} \mathrm{a}$ & $1,38 \mathrm{~A} \mathrm{a}$ & $1,35 \mathrm{AB}$ a & $1,30 \mathrm{~A} \mathrm{a}$ \\
\hline $20,0-25,0$ & $1,36 \mathrm{~A} \mathrm{a}$ & $1,39 \mathrm{~A} \mathrm{a}$ & $1,39 \mathrm{~A} \mathrm{a}$ & $1,37 \mathrm{AB}$ a & $1,37 \mathrm{~A} \mathrm{a}$ \\
\hline $25,0-30,0$ & $1,32 \mathrm{~A} \mathrm{a}$ & $1,34 \mathrm{~A} \mathrm{a}$ & $1,39 \mathrm{~A} \mathrm{a}$ & $1,29 \mathrm{~B} \mathrm{a}$ & $1,27 \mathrm{~A} \mathrm{a}$ \\
\hline $30,0-35,0$ & $1,34 \mathrm{~A} \mathrm{ab}$ & $1,31 \mathrm{~A} \mathrm{~b}$ & $1,35 \mathrm{~A} \mathrm{ab}$ & $1,49 \mathrm{~A} \mathrm{a}$ & $1,36 \mathrm{~A} \mathrm{ab}$ \\
\hline \multicolumn{2}{|c|}{$\mathrm{F}($ herb $)-2,72^{\mathrm{ns}}$} & \multicolumn{2}{|c|}{$\mathrm{F}$ (prof) $-3,83^{* *}$} & \multicolumn{2}{|c|}{$\mathrm{F}($ Interação $)-2,17^{* *}$} \\
\hline \multicolumn{2}{|c|}{ CV $(\%)$ herb $-9,03$} & \multicolumn{4}{|c|}{ CV $(\%)$ prof $-5,48$} \\
\hline \multicolumn{6}{|c|}{ DMS (prof) $-0,16$} \\
\hline \multicolumn{6}{|c|}{ DMS (herb) $-0,15$} \\
\hline
\end{tabular}

1/ Médias seguidas de mesma letra não diferem significativamente entre si pelo teste de Tukey a 5\% de probabilidade. Letras maiúsculas, na coluna, comparam as diferentes profundidades. Letras minúsculas, na linha, comparam os tratamentos com aplicação dos herbicidas. **, * significativo a $1 \%$ de probabilidade pelo teste de Tukey; ${ }^{\text {ns }}$ não significativo a $5 \%$ de probabilidade pelo teste de Tukey.

situações com umidade no início seguida de um período de seca.

Os dados da última amostragem, realizada após acúmulo de $106 \mathrm{~mm}$ de precipitação (Tabela 7), mostrara que o sulfentrazone reduziu a matéria seca de $I$. nil na faixa de $0,0-$ $2,5 \mathrm{~cm}$, estendendo até $5,0 \mathrm{~cm}$ quando comparado à testemunha. A adição do adjuvante não alterou esse comportamento do herbicida. O amicarbazone, sob essa precipitação, com ou sem adjuvante, não afetou a matéria seca das plântulas de $I$. nil. A adição de óleo mineral proporcionou redução significativa da matéria. Contudo, nessas profundidades não houve diferença em relação à testemunha. Isso se deve, provavelmente, ao fato de o herbicida apresentar alta solubilidade, facilitando sua lixiviação por todo o perfil do solo sob essa precipitação e, consequentemente, não afetando a matéria seca das plantas-teste.

Com base nos dados obtidos, pode-se concluir que o herbicida sulfentrazone lixiviou até a profundidade de $10 \mathrm{~cm}$ mesmo com $106 \mathrm{~mm}$ de precipitação, independentemente da adição do adjuvante (óleo mineral). O herbicida amicarbazone não afetou o desenvolvimento das plântulas de S. bicolor. Para I. nil, o herbicida sob uma precipitação de $35 \mathrm{~mm}$ reduziu o desenvolvimento das plântulas, independentemente da profundidade e sem efeito diferenciado do óleo. Ao simular $67 \mathrm{~mm}$ de precipitação, o herbicida lixiviou pelo solo; o óleo mineral o manteve na camada mais superficial, enquanto a chuva simulada em $106 \mathrm{~mm}$ promoveu a lixiviação total do herbicida e não se constatou efeito do óleo.

\section{AGRADECIMENTOS}

À UNION AGRO Ltda., pelo apoio à realização deste trabalho; e à Usina Bonfim (Cosan), pela cessão da área.

\section{LITERATURA CITADA}

ALVES, P. L. C. A.; MARQUES JR., J.; FERRAUDO, A. S. Soil attributes and the efficiency of sulfentrazone on control of purple nutsedge (Cyperus rotundus L.). Sci. Agric., v. 61, n. 3, p. 319-325, 2004.

DIAS, T. C. S. et al. Efeito da interação entre o herbicida Dinamic (amicarbazone) e cultivo do solo sobre o controle de plantas daninhas em pré-emergência. CONGRESSO BRASILEIRO DA CIÊNCIA DAS PLANTAS DANINHAS, 25., 2006, Brasília. Anais... Brasília: Sociedade Brasileira da Ciência das Plantas Daninhas, 2006. CD-ROM.

GIMENES, R. Dinamic: O novo herbicida da Hokko do Brasil para cana-de-açúcar. STAB, v. 22, n. 4, p. 23-24, 2004.

GRAHAM-BRYCE, I. G. The behaviour of pesticides in soil. In: GREENLAND, D. J.; HAYES, M. H. B. (Eds.). The chemistry of soil processes. New York: J. Wiley, 1981. p. $621-670$. 
NEGRISOLI, E. et al. Controle de plantas daninhas pelo amicarbazone aplicado na presença de palha de cana-de-açúcar. Planta Daninha, v. 25, n. 3, p. 603-611, 2007.

RODRIGUES, B. N. et al. Influência da cobertura morta no comportamento do herbicida sulfentrazone. Planta Daninha, v. 17, n. 3 , p. $445-458,1999$

RODRIGUES, B. N.; ALMEIDA, F. S. Guia de herbicidas. 5.ed. Londrina: Edição dos Autores, 2005. p. 484-490.
ROSSI, C. V. S.; ALVES, P. L. C. A.; MARQUES JÚNIOR, J. Mobilidade do sulfentrazone em Latossolo Vermelho e em Chernossolo. Planta Daninha, v. 21, n. 1, p. 111-120, 2003.

ROSSI, C. V. S. et al. Mobilidade do sulfentrazone no perfil de classes de solos. R. Bras. Herbic., v. 4, n. 1, p. 65-67, 2005.

VIVIAN, R. et al. Persistência de sulfentrazone em Argissolo Vermelho-Amarelo cultivado com cana-de-açúcar. Planta Daninha, v. 24, n. 4, p. 741-750, 2006 